Check for updates

Cite this: J. Mater. Chem. A, 2019, 7, 27124

Received 13th September 2019 Accepted 14th November 2019

DOI: $10.1039 / c 9 t a 10128 d$

rsc.li/materials-a

\section{Suppression of thermal conductivity without impeding electron mobility in n-type XNiSn half- Heusler thermoelectrics $\dagger$}

\begin{abstract}
S. A. Barczak, ${ }^{a}$ R. J. Quinn, (D) a J. E. Halpin, (D) ${ }^{b}$ K. Domosud, ${ }^{\text {C }}$ R. I. Smith, (D) d
A. R. Baker, ${ }^{e}$ E. Don, ${ }^{f}$ I. Forbes, ${ }^{9}$ K. Refson, ${ }^{c}$ D. A. MacLaren iD ${ }^{* b}$ and J. W. G. Bos (iD *a

We outline a strategy to improve the thermoelectric performance of $n$-type XNiSn based half-Heusler alloys through $\mathrm{Cu}$ doping into vacant tetrahedral sites. A comprehensive combination of structural characterisation and modelling is employed to discriminate the competing mechanisms for thermoelectric enhancement. During synthesis a mineralising effect occurs that improves the homogeneity of the alloying elements $\mathrm{Ti}, \mathrm{Zr}$ and $\mathrm{Hf}$, and promotes grain growth, leading to a doubling of the electron mobility. In the formed materials, $\mathrm{Cu}$ is a strong $\mathrm{n}$-type dopant, like $\mathrm{Sb}$, but occupies the interstitial site and strongly enhances phonon scattering without diminishing carrier mobility (in contrast to interstitial $\mathrm{Ni}$ ). Simultaneous alloying with $\mathrm{Ti}, \mathrm{Zr}$ and $\mathrm{Hf}$ serves to minimise the thermal conductivity via regular mass disorder and strain effects. A best electronic power factor, $S^{2} / \rho$, of $3.6 \mathrm{~mW} \mathrm{~m}^{-1} \mathrm{~K}^{-2}$ and maximum $Z T$ of 0.8 at $773 \mathrm{~K}$ were observed for a $\mathrm{Ti}_{0.5} \mathrm{Zr}_{0.25} \mathrm{Hf}_{0.25} \mathrm{NiCu}_{0.025} \mathrm{Sn}$ composition, enabling promising device power densities of $\sim 6 \mathrm{~W} \mathrm{~cm}^{-2}$ and $\sim 8 \%$ conversion efficiency from a $450 \mathrm{~K}$ gradient. These findings are important because they provide new insight into the mechanisms underpinning high $Z T$ in the XNiSn system and indicate a direction for further improvements in thermoelectric performance.
\end{abstract}

\section{Introduction}

Thermoelectric generators are a renewable energy technology that can increase the efficiency of power generation and usage. ${ }^{1,2}$ However, widespread application has been limited by the availability of high-performing materials that also satisfy the engineering requirements resulting from harvesting heat. Half-Heuslers (HHs) present arguably the best compromise between good thermoelectric efficiencies, temperature stability, mechanical properties, scalability and use of relatively abundant non-toxic elements. ${ }^{3-6} \mathrm{HH}$ p-types have been developed rapidly over the past 5 years with thermoelectric figures of merit

${ }^{a}$ Institute of Chemical Sciences, Centre for Advanced Energy Storage and Recovery, School of Engineering and Physical Sciences, Heriot-Watt University, Edinburgh, EH14 4AS, UK. E-mail: j.w.g.bos@hw.ac.uk

${ }^{b} S U P A$, School of Physics and Astronomy, University of Glasgow, Glasgow G12 8QQ, UK. E-mail: dmaclaren@physics.org

${ }^{c}$ Department of Physics, Royal Holloway University London, Egham, TW20 OEX, UK ${ }^{d}$ ISIS Facility, Rutherford Appleton Laboratory, Harwell Oxford, Didcot OX11 OQX, UK ${ }^{e}$ Diamond Light Source, Harwell Campus, Didcot, Oxfordshire, OX11 ODE, UK ${ }^{f}$ SemiMetrics Ltd., Kings Langley WD4 9WB, UK

${ }^{g}$ Department of Physics and Engineering, Northumbria University, Newcastle NE1 8ST, $U K$

$\dagger$ Electronic supplementary information (ESI) available: Tables with detailed structural information, details of the SPB analysis, Rietveld fits to SXRD and NPD data and additional electron microscopy images. See DOI: 10.1039/c9ta10128d around $Z T \sim 1.5$ reported for $\mathrm{X}^{\prime} \mathrm{FeSb}\left(\mathrm{X}^{\prime}=\mathrm{Nb}\right.$, Ta) and $\mathrm{ZrCoBi}-$ based compositions. ${ }^{7-12}$ By contrast, the long-established n-type XNiSn compositions ( $\mathrm{X}=\mathrm{Ti}, \mathrm{Zr}, \mathrm{Hf}$ ) have proved more difficult to optimise with $Z T$ just over a value of $1,{ }^{13-15}$ and possibly as high as $Z T \sim 1.5 .{ }^{16}$ Here, $Z T=\left(S^{2} / \rho \kappa\right) T$, where $S$ is the Seebeck coefficient, $\rho$ is the electrical resistivity, $\kappa$ is the sum of the lattice $\left(\kappa_{\text {lat }}\right)$ and electronic $\left(\kappa_{\mathrm{el}}\right)$ thermal conductivities, $T$ is the absolute temperature and $Z T$ is the preferred figure of merit because it is dimensionless.

In general, HHs are characterised by large power factors, $S^{2} /$ $\rho$, and are limited by relatively large $\kappa_{\text {lat }}$ values. Most attention has therefore focused on finding new routes to enhance phonon scattering in these materials. The main route has been alloying with isovalent elements, leaving the electrical properties largely unaffected..$^{17}$ Other successful routes are to enhance boundary scattering through reduction of the average grain size ${ }^{\mathbf{1 8 - 2 0}}$ and by exploiting out-of-equilibrium approaches and segregation to create nanostructured materials. ${ }^{21-40}$ We have demonstrated that TiNiSn is unique in its ability to accommodate significant amounts of interstitial $\mathrm{Ni}$ and $\mathrm{Cu}$ metals ( $\sim 10 \%$ site occupancy), ${ }^{\mathbf{4 1 - 4 4}}$ whereas ZrNiSn and HfNiSn have far lower capacities $(<2-3 \%)$ under the same preparation conditions. ${ }^{45}$ These interstitials form highly effective phonon scattering centres, e.g. $\kappa_{\text {lat }} \sim 4.5 \mathrm{~W} \mathrm{~m}^{-1} \mathrm{~K}^{-1}$ for $\sim 5 \%$ interstitial site occupancy, with a much stronger impact than expected from alloy phonon scattering only. ${ }^{43,46}$ In addition, $\mathrm{Cu}$ interstitials are effective ntype dopants and lead to rapid $S^{2} / \rho$ improvements, enabling 
$Z T=0.6$ at $773 \mathrm{~K}$ and commercially viable power outputs. ${ }^{43}$ However, our previous study did not address the impact of interstitial $\mathrm{Cu}$ on the electron mobility. A further benefit of using excess $\mathrm{Cu}$ is that it we have found it to reside as coherent metallic 'wetting layers' at grain boundaries after hot-pressing, which appears to reduce grain boundary resistances. ${ }^{\mathbf{4 3}}$

This manuscript addresses the question of the impact of the combined use of X-site alloying and interstitial metals in the $\mathrm{Ti}_{0.5} \mathrm{Zr}_{0.25} \mathrm{Hf}_{0.25} \mathrm{NiCu}_{y} \mathrm{Sn}$ system. The $\mathrm{X}$-site composition was chosen to afford large mass and size disorder and corresponds to ratios used in studies reporting high $Z T$ values. ${ }^{15,16,21,22}$ An interstitial range of $0 \leq y \leq 0.075$ was chosen as this covers the range of useful n-type doping and reduction of $\kappa_{\text {lat }}$ for the $\mathrm{TiNiCu}_{y} \mathrm{Sn}$ series. We have used extensive characterisation including synchrotron X-ray, neutron powder diffraction, scanning and transmission electron microscopies and spectroscopies, thermoelectric property and Hall measurements, single parabolic band modelling and density functional calculations. These give new insights into the atomic-scale structure and microstructures and the impact on the electrical and thermal transport, providing new guidance to develop strategies for optimising thermoelectric performance in $\mathrm{HH}$ materials. A highest $Z T$ of 0.8 at $773 \mathrm{~K}$ was observed, enabling a $\sim 6 \mathrm{~W} \mathrm{~cm}^{-2}$ leg power output with $\sim 8 \%$ efficiency. In terms of overall performance, the main impact of alloying is an increase in efficiency (from $\sim 6 \%$ ), while the estimated power output is similar (6-7 $\mathrm{W} \mathrm{cm}^{-2}$ without alloying). The analysis suggests that further improvements in performance, approaching the state-of-the-art, are possible with improvements to sample microstructure and homogenisation, making this a compelling materials system for commercial exploitation.

\section{Experimental}

\section{Synthesis}

Samples with composition $\mathrm{Ti}_{0.5} \mathrm{Zr}_{0.25} \mathrm{Hf}_{0.25} \mathrm{NiCu}_{y} \mathrm{Sn} \quad y=0$, $0.025,0.05$ and 0.075 ) with masses of $5 \mathrm{~g}$ were prepared by solidstate reaction of elemental powders purchased from Alfa Aesar of $>99.5 \%$ purity. The elemental powders were mixed using an agate pestle and mortar, then cold pressed into $13 \mathrm{~mm}$ diameter disks. These disks were wrapped in tantalum foil, sealed in an evacuated silica ampoule and sintered at $1123 \mathrm{~K}$ for 24 hours. The disks were then reground, repressed, resealed and annealed for $1123 \mathrm{~K}$ for 14 days. For the purposes of property measurement, the samples were then hot pressed for 20 minutes under an argon atmosphere, using an applied pressure of $80 \mathrm{MPa}$ and temperature of $1173 \mathrm{~K}$, yielding near theoretical densities for the $\mathrm{Cu}$ containing samples. Note that two additional samples were prepared for the Hall measurements $(y=$ 0.0125 and $y=0.0375$ ) using an identical route.

\section{Powder diffraction}

Samples were initially characterised using powder X-ray diffraction (XRD). Data were collected over 8 hours using a Bruker D8 Advance diffractometer with monochromated $\mathrm{Cu} \mathrm{K}_{\alpha 1}$ radiation. Room temperature neutron powder diffraction (NPD) data from 1-2 $\mathrm{g}$ of finely ground powders were collected using the Polaris instrument at the ISIS facility, Rutherford Appleton Laboratory, UK. Rietveld refinement of NPD data was performed using the General Structure Analysis System (GSAS) and its user interface EXPGUI. ${ }^{\mathbf{4 7}, 48}$ Synchrotron X-ray diffraction (SXRD) data $(\lambda=0.825921 \AA$, step size $0.002^{\circ}$ ) were collected on the high-resolution powder diffractometer beamline I11 at the Diamond Light Source, UK. Rietveld refinement of the SXRD data were performed using the TOPAS Academic software package and input file editor jEdit. ${ }^{49}$

\section{Microscopy}

A Thermo Fischer Helios Dualbeam microscope was used to analyse the mechanically-polished surfaces of cut ingots by Scanning Electron Microscopy (SEM). It was also equipped with a Bruker XFlash $100 \mathrm{~mm}^{2}$ detector that was used for energy dispersive X-ray spectroscopy (EDS) compositional analysis. A Bruker eFlash FS electron back-scattered diffraction (EBSD) detector was used to assess the granularity of samples, with Bruker ESPRIT software indexing the EBSD patterns, mapping the crystallographic orientation across the exposed sample surface and $\mathrm{ATOM}^{50}$ software generating grain boundary reconstructions. Scanning transmission electron microscopy (STEM) was performed on a JEOL ARM instrument operated at $200 \mathrm{keV}$ and equipped with a cold field emission gun. Electron energy loss spectroscopy (EELS) datasets were acquired using the Spectrum Imaging (SI) methodology ${ }^{51}$ with a Gatan Quantum spectrometer and typically alongside high angle annular dark field (HAADF) images. Analysis of EELS spectra was performed using DigitalMicrograph software: SI spectra were aligned by their zero-loss-peak, de-noised by X-rays/ artefact spikes removal then using principal component analysis, deconvolved to remove plural scattering effects, background-subtracted, analysed using the cross-sectional data within DigitalMicrograph and finally low-pass filtered to produce atomic-resolved elemental maps.

\section{Thermoelectric properties}

The electrical resistivity $(\rho)$ and Seebeck coefficient $(S)$ were measured on bar-shaped specimens $\left(\sim 1.5 \times 2 \times 10 \mathrm{~mm}^{3}\right)$ between $313 \mathrm{~K}$ and $773 \mathrm{~K}$ in a He atmosphere using a Linseis LSR-3 instrument. The thermal diffusivity $(\alpha)$ was measured using disks of $\sim 13 \mathrm{~mm}$ diameter and $\sim 1.5 \mathrm{~mm}$ thickness between $323 \mathrm{~K}$ and $773 \mathrm{~K}$ under vacuum using a Linseis LFA1000 instrument. The disks were coated using a carbon spray to reduce error in emissivity. The heat capacity, $C_{\mathrm{p}}(T)$, of $\mathrm{Ti}_{0.5^{-}}$ $\mathrm{Zr}_{0.25} \mathrm{Hf}_{0.25} \mathrm{NiSn}$ was measured using a PerkinElmer DSC 8500 instrument. Hall measurements were taken using the method of van der Pauw using a magnetic field of $\pm 1 \mathrm{~T}$ and a DC current of $\leq \pm 100 \mathrm{~mA}$, leading to Hall voltages of $\pm 0.1-10 \mathrm{mV}$, measured using a nanovoltmeter. Silver paint was used to make contacts on the corners of $\sim 5 \times 5 \times 1.5 \mathrm{~mm}^{3}$ squares, which were clamped into a probe card for measurement.

\section{DFT calculations}

Electronic structure calculations were performed using the CASTEP first principles simulation package. ${ }^{52}$ The supercell 
approximation was used with $2 \times 2 \times 2$ multiples of the primitive cell (fcc) of stoichiometric TiNiSn, containing 24 atoms to model the $\mathrm{Ti}_{0.5} \mathrm{Zr}_{0.5} \mathrm{NiSn}$ composition and 1 additional atom filling a vacancy site for compositions with interstitials: the equivalent of 0.125 excess $\mathrm{Ni}$ or $\mathrm{Cu}$. Calculations used the $\mathrm{PBE}^{53}$ general gradient approximation treatment of the exchangecorrelation functional and an ultrasoft pseudopotential set, which was generated on the fly using CASTEP version 18.1. Convergence parameters for the plane-wave cut off were determined to be in the range of $600-800 \mathrm{eV}$ and the sampling was performed on a $4 \times 4 \times 4$ Monkhorst-Pack $k$-point sampling grid. This corresponds to a total energy convergence of $0.5 \mathrm{meV}$ atom $^{-1}$ or better. Structural relaxation was performed using the LBFGS optimization method as implemented in CASTEP. The force and stress convergence for the geometry optimisation were $0.03 \mathrm{eV} \AA^{-1}$ and 0 : 05 GPa respectively. The electronic band structures were unfolded onto the primitive cell using the bs_sc2pc code, ${ }^{54}$ which implements the scheme described by Popescu and Zunger, ${ }^{55}$ modified for use with ultrasoft pseudopotentials. The effective band structure for the relaxed structure was calculated along the $\Gamma-X-\Gamma-L-W-X$ path in the
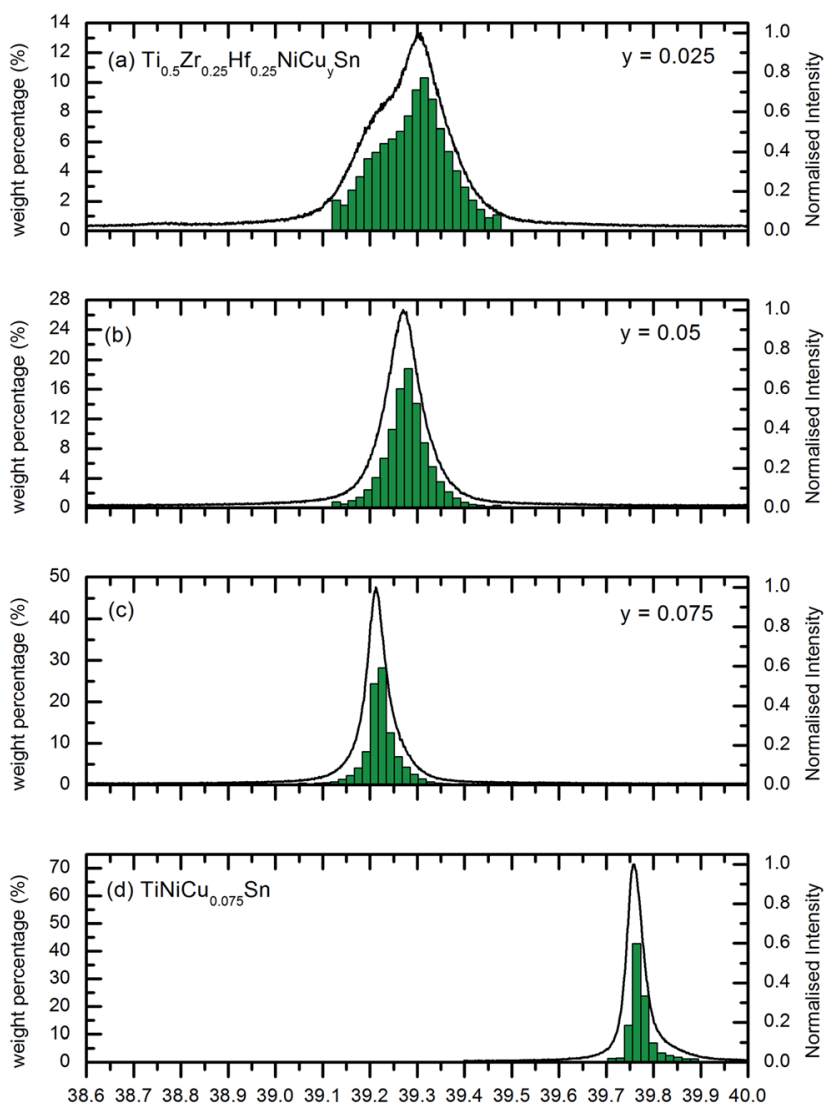

$2 \theta$

Fig. 1 Structural evolution from synchrotron $X$-ray powder diffraction. Panels $(a-c)$ show a close-up of the half-Heusler (422) reflection for selected $\mathrm{Ti}_{0.5} \mathrm{Zr}_{0.25} \mathrm{Hf}_{0.25} \mathrm{NiCu}_{y} \mathrm{Sn}$ samples. The histograms indicate the number and abundance of the $\mathrm{HH}$ phases needed to fit the peak shape. The HH peak width corresponds to the instrumental resolution. Panel (d) shows identical data for $\mathrm{TiNiCu}_{0.075} \mathrm{Sn}$, which does not have $\mathrm{X}$-site phase segregation, for comparison. primitive Brillouin zone using the same convergence parameters as for the structural relaxation.

\section{Results}

\section{Structural properties}

The SXRD data (Fig. S1 $\dagger$ ) shows the successful formation of $\mathrm{HH}$ phases, and though the $y=0.075$ sample shows sharp peaks consistent with a single $\mathrm{HH}$ phase, the $x=0.05$ and 0.025 samples show substantial peak broadening, consistent with the formation of multiple $\mathrm{HH}$ phases due to the poor mixing of the X-site elements. ${ }^{22,23}$ Fig. 1 shows the decreasing SXRD peak width of the (4 4 2) reflection with increasing $\mathrm{Cu}$ content and the trend towards a single $\mathrm{HH}$ phase. The peak shape was fitted using multiple $\mathrm{HH}$ phases, with a lattice parameter difference of $\Delta a=0.0025 \AA$ and fixed profile parameters so that the parent material TiNiSn is described as a single $\mathrm{HH}$ phase. ${ }^{46}$ The increasing homogenisation is quantified by the reduced number of phases required to describe the peak which, in turn, confirms that $\mathrm{Cu}$ causes a mineralising effect. Mineralising effects are commonly observed for reactions that exploit a molten flux (e.g. a NaCl-KCl eutectic) ${ }^{56}$ that partially dissolves the sample and promotes the reaction kinetics. Here, this occurs upon introduction of $\mathrm{Cu}$, however, the melting point of elemental $\mathrm{Cu}(1358 \mathrm{~K})$ is above the sintering temperature, suggesting that the mineralisation may instead be caused by a $\mathrm{Cu}-$ Sn alloy, which are observed at trace amounts in the EDS elemental mapping (Fig. 2) and which have <1123 K melting points. ${ }^{57}$ Analysis of NPD data (Fig. S2 $\dagger$ ) with its lower $d$-spacing resolution required only a single $\mathrm{HH}$ phase, enabling the

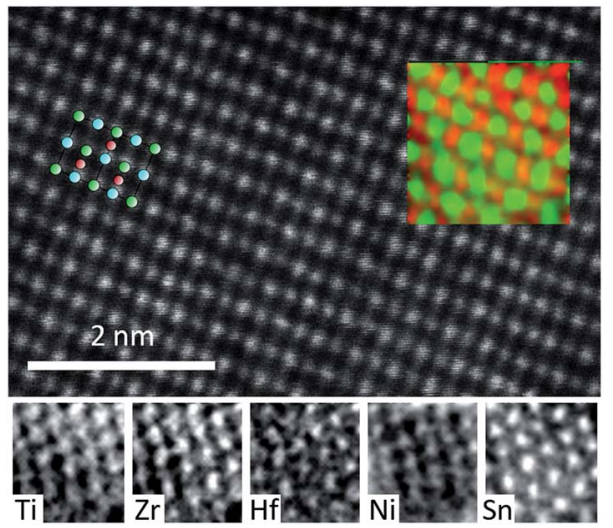

Fig. 2 HAADF-STEM image resolving the atomic columns in a $\mathrm{Ti}_{0.5^{-}}$ $\mathrm{Zr}_{0.25} \mathrm{Hf}_{0.25} \mathrm{NiCu}_{0.025} \mathrm{Sn}$ sample, viewed along a [110] direction and dominated by signals from the heaviest $\mathrm{Sn}, \mathrm{Zr}$ and $\mathrm{Hf}$ atoms ( $\mathrm{Cu}$ and $\mathrm{Ni}$ have comparatively low atomic number and are not readily observed under these acquisition conditions). The panels below are EELS maps collected by spectrum imaging and indicate the elemental distributions within the coloured region of the STEM image, with the colours of that region deriving from the (red) summed $\mathrm{Ti}, \mathrm{Zr}$ and $\mathrm{Hf}$ signals and (green) Sn signals. EELS maps derive from the background-subtracted, deconvolved $L_{2,3}$ edges of $\mathrm{Ti}, \mathrm{Zr}, \mathrm{Ni}$ and the $\mathrm{M}_{4,5}$ edges of $\mathrm{Hf}$ and $\mathrm{Sn}$. The maps indicate occupation of the same site by $\mathrm{Ti}, \mathrm{Zr}$ and Hf. Some sample drift is evident in the spectrum images. A cartoon of the [110]oriented unit cell is also superimposed on the left of the HAADF image, with $\mathrm{Ti} / \mathrm{Zr} / \mathrm{Hf}$ atoms in green, $\mathrm{Sn}$ in cyan and $\mathrm{Ni}$ in red. 
experimental compositions to be verified. For these fits, the $\mathrm{Ni}$ and $\mathrm{Sn}$ sites were fixed at $100 \%$ occupancy, the $\mathrm{Zr}$ and $\mathrm{Hf}$ ratio was fixed at $1: 1$, while the Cu occupancy on the interstitial site and the $\mathrm{Ti}$ to $\mathrm{Zr} / \mathrm{Hf}$ ratio on the $\mathrm{X}$-site were refined freely. This confirms that the compositions of the samples are close to the nominal values, and that up to $0.075 \mathrm{Cu}$ has been successfully incorporated into the vacant tetrahedral site of the structure. The occupancy of the X-sites is also confirmed to be close to the nominal split between $\mathrm{Ti}, \mathrm{Zr}$ and $\mathrm{Hf}$. Small amounts of $\mathrm{HfO}_{2}$ and $\mathrm{Ni}_{3} \mathrm{Sn}_{2}(<1-2 \mathrm{wt} \%)$ were observed for $y=0.025$ and $y=0.05$, but these have largely disappeared for the higher doped $y=$ 0.075 sample (Fig. S1 and S2 $\dagger$ ), in keeping with the improved sample quality. The full results of the fits, including structural parameters and fit statistics are provided in Table S1. $\dagger$

On atomic length-scales, occupancy of the X-site by $\mathrm{Ti}, \mathrm{Zr}$ and $\mathrm{Hf}$ was confirmed by direct STEM imaging, as shown in Fig. 2. This figure presents a spectrum image of a section of an [110]-oriented $\mathrm{Ti}_{0.5} \mathrm{Zr}_{0.25} \mathrm{Hf}_{0.25} \mathrm{NiCu}_{0.025} \mathrm{Sn}$ crystal, highlighting
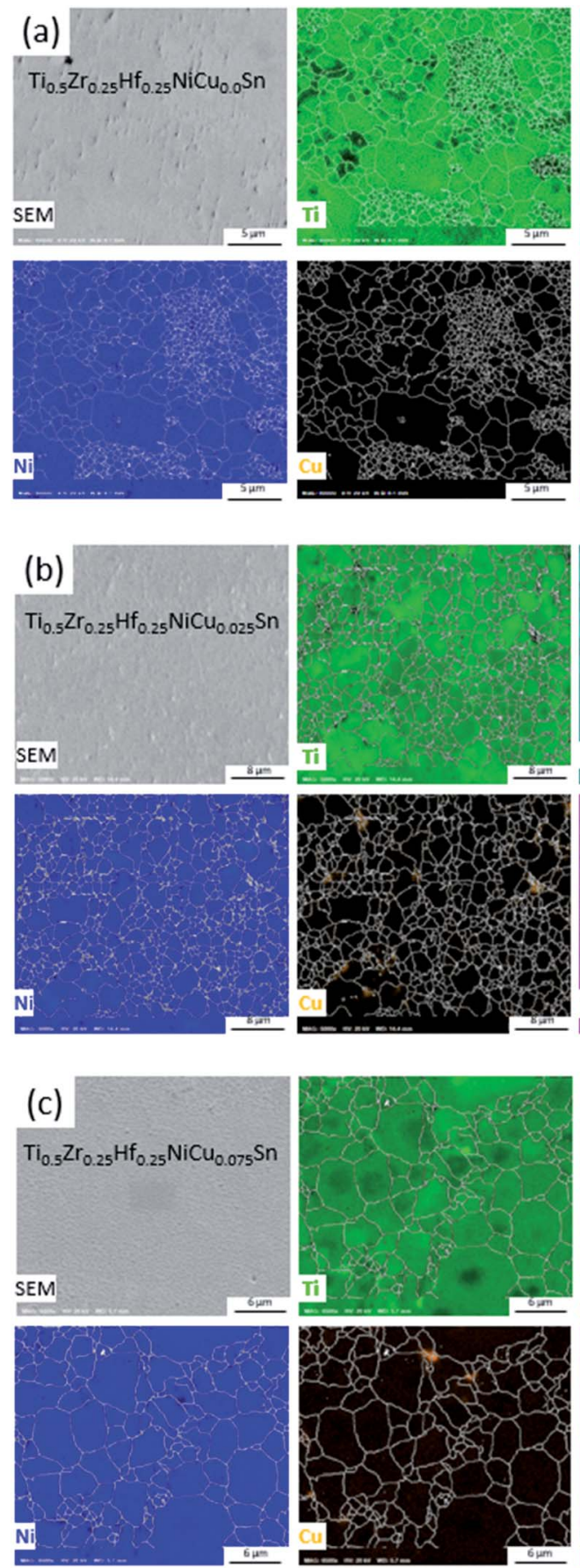
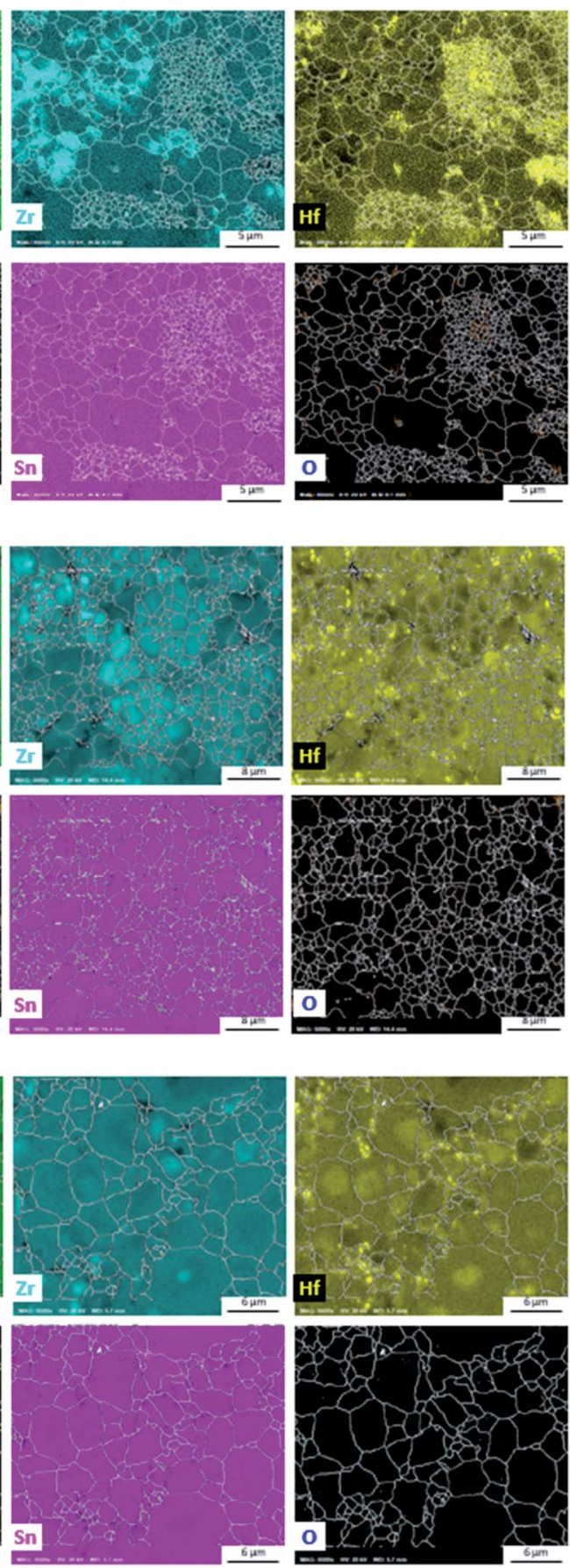

Fig. 3 SEM analysis of (a) $\mathrm{Ti}_{0.5} \mathrm{Zr}_{0.25} \mathrm{Hf}_{0.25} \mathrm{NiCu}_{0.0} \mathrm{Sn}$ (b) $\mathrm{Ti}_{0.5} \mathrm{Zr}_{0.25} \mathrm{Hf}_{0.25} \mathrm{NiCu}_{0.025} \mathrm{Sn}$ and (c) $\mathrm{Ti}_{0.5} \mathrm{Zr}_{0.25} \mathrm{Hf}_{0.25} \mathrm{NiCu}_{0.075} \mathrm{Sn}$ samples. Each group of panels comprises an SEM image and EDS-derived maps of elemental distribution for Ti, Zr, Hf, Ni, Cu, Sn and O, each superimposed with grainboundary maps derived from EBSD mapping. See text for details. 
the atomic locations of individual elements. The sample was approximately $50 \mathrm{~nm}$ thick and the atomic features in the main HAADF image derive from columns of several hundred atoms each, with the heaviest ( $\mathrm{Zr}, \mathrm{Sn}$, Hf) elements dominating the image contrast due to the strong dependence on atomic number in this imaging mode. Despite some sample drift during acquisition, the EELS SI panels clearly locate $\mathrm{Ti}, \mathrm{Zr}$ and Hf signals at the same atomic columns, suggesting mixed occupancy of the X-site. Sn signals are located on different columns, consistent with the Z-site of the $\mathrm{HH}$ cell whilst the Ni signal is weaker but consistent with tetrahedral site occupation. In contrast, mineralisation effects due to $\mathrm{Cu}$ addition are evident on micrometre length-scales, as demonstrated by the SEM data of Fig. 3. This figure presents elemental maps, derived from EDS data, collected from $y=0,0.025$ and 0.075 samples, with a separate map for each of the main elements in addition to oxygen, which can be problematic in Ti-bearing Heusler alloys $^{58}$ but here is at inconsequential levels. The differences between samples are stark. Without $\mathrm{Cu}$, segregation of $\mathrm{Ti}, \mathrm{Zr}$ and $\mathrm{Hf}$ across micrometres is evident and the maps of their distributions are complementary: where one of these elements is strong, the other two are weak in signal intensity. In addition, the grain sizes are inhomogeneous, with Hf-rich grains the smallest, presumably because sintering is limited by the relatively high melting point and consequently low diffusion rates of Hf. Addition of $\mathrm{Cu}(y=0.025$ sample, middle panels of Fig. 3) reduces the elemental segregation effects to produce a more homogeneous alloy with larger grains (in agreement with the SXRD data of Fig. 1), trends that are continued in the $y=0.075$ sample (lower panels of Fig. 3), where grains have increased by an order of magnitude in diameter, elemental distributions are more homogeneous and segregation within grains becomes evident. The formation of grains with a core-shell structure for $y$ $=0.075$ suggests that segregation within the $y=0.075$ sample is
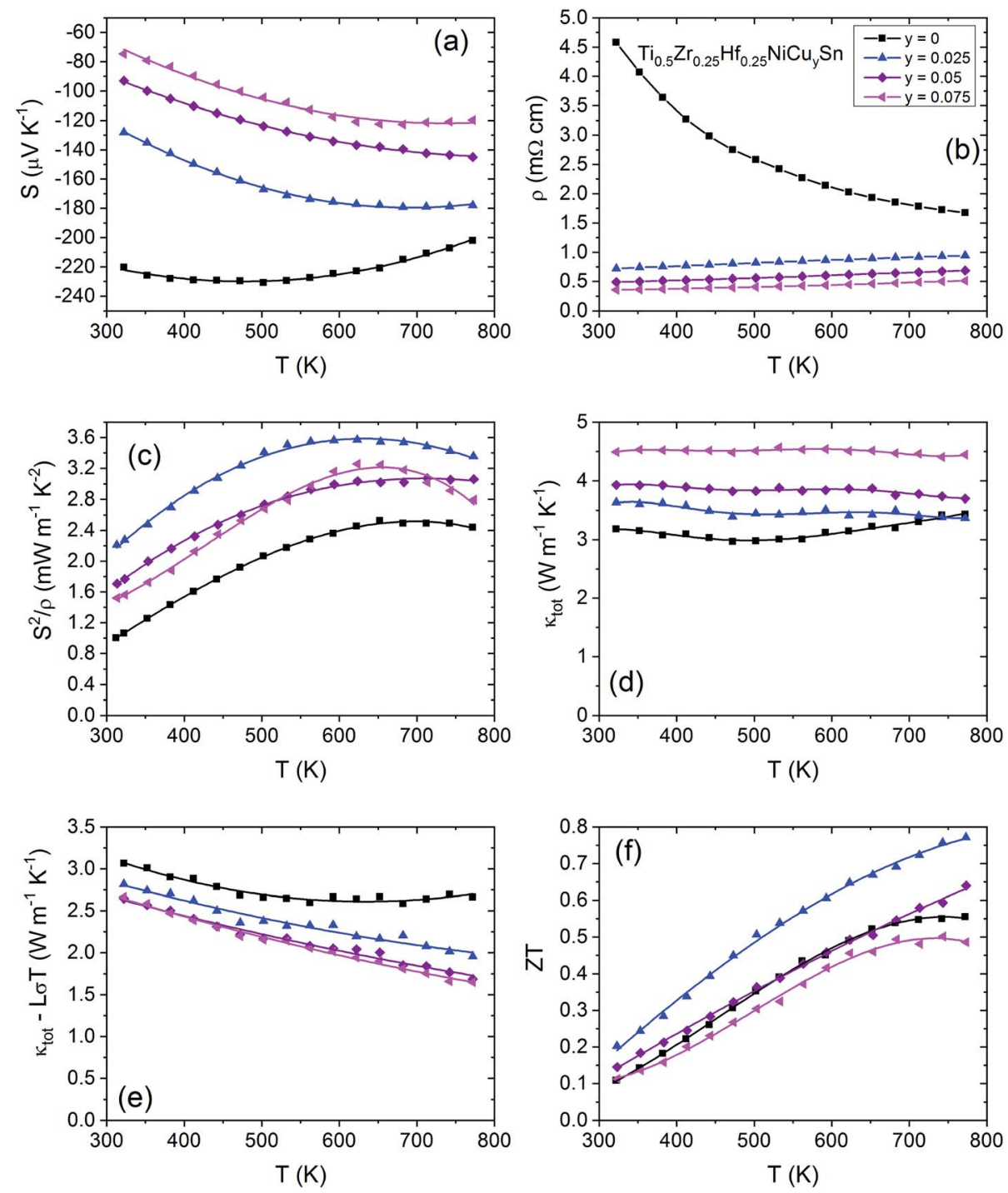

Fig. 4 Overview of the thermoelectric properties for the $\mathrm{Ti}_{0.5} \mathrm{Zr}_{0.25} \mathrm{Hf}_{0.25} \mathrm{NiCu}_{\mathrm{y}} \mathrm{Sn}$ half-Heusler alloys. Panels (a-f) show the temperature dependence of the Seebeck coefficient $(S)$, electrical resistivity $(\rho)$, power factor $\left(S^{2} / \rho\right)$, total thermal conductivity $(\kappa)$, lattice thermal conductivity $\left(\kappa_{\text {lat }}\right)$ and dimensionless figure of merit $(Z T)$. The legend is common to all panels. 
driven by thermodynamic rather than kinetic effects (such as diffusion limitations). Previous studies have shown that $\mathrm{Hf}$ crystallises first from the melt to form bcc inclusions that act as nucleation seeds for grains. ${ }^{22}$ Here, the cores of larger grains are rich in both $\mathrm{Zr}$ and $\mathrm{Hf}$ and the shells are conversely rich in $\mathrm{Ti}$, in accordance with the difference in elemental melting points, producing a structure similar to that seen in peritectic phase segregation from the melt. ${ }^{21,22}$ EBSD data does not indicate a substantial change in crystallography within grains, suggesting that the lattice is coherent throughout, which would account for the sharpened SXRD peaks for this composition. Higher spatial resolution analysis of phase segregation in the $y$ $=0.025$ sample is presented in Fig. S3 $\uparrow$ and shows evidence of segregation within grains; and a quantitative analysis of grain sizes for the $y=0.025$ and 0.075 samples is presented in Fig. S4. $\uparrow$ EBSD data in the latter confirm that the addition of $\mathrm{Cu}$ to the HH system has a mineralising effect on grain size, leading to larger grains upon annealing, with the mean size of grains more than doubling between the $y=0.025$ and 0.075 samples.

\section{Thermoelectric properties}

The temperature dependent electronic and thermal transport properties for the $\mathrm{Ti}_{0.5} \mathrm{Zr}_{0.25} \mathrm{Hf}_{0.25} \mathrm{NiCu}_{y} \mathrm{Sn}(0 \leq y \leq 0.075)$ samples are shown in Fig. 4, while the room temperature thermoelectric values are summarized in Table S2. $\dagger$ In all cases, the addition of $\mathrm{Cu}$ abruptly alters the measured parameters and thereafter there are smooth trends with increasing $\mathrm{Cu}$ content. This reflects the clear change in microstructure between the $y=0$ and $y=0.025$ samples in Fig. 3, in addition to differences in carrier concentration. The Seebeck coefficient $(S)$ is negative for all samples, consistent with majority n-type conduction (Fig. 4a). There are large changes in both $S$ and the electrical resistivity $(\rho)$ with even low $\mathrm{Cu}$ doping, (Fig. 4b) showing that the addition of interstitial $\mathrm{Cu}$ electron-dopes the material and leads to a rapid transition from semiconducting to metal-like degenerate semiconductor behaviour, and simultaneously reduces $\rho$ through mineralisation effects (discussed below). Using the $\rho(T)$ behaviour of the semiconducting $y=0$ sample, we find that the bandgap is $E_{\mathrm{g}} \sim 0.1 \mathrm{eV}$, which is in good agreement with our supercell DFT calculations that show the emergence of in-gap states due to interstitial $\mathrm{Ni}$, leading to a small indirect bandgap $(<0.1 \mathrm{eV})$ compared to $\sim 0.5 \mathrm{eV}$ for perfect TiNiSn. The transition from semiconducting to degenerate semiconductor behaviour leads to a large increase in the power factor $\left(S^{2} / \rho\right)$ for all $\mathrm{Cu}$ doped samples (Fig. 4c). All doped samples show an improved power factor with the $y=0.025$ sample achieving $S^{2} / \rho=3.6 \mathrm{~mW} \mathrm{~m}^{-1} \mathrm{~K}^{-2}$ at $623 \mathrm{~K}$, a significant improvement compared to the $2.5 \mathrm{~mW} \mathrm{~m}^{-1} \mathrm{~K}^{-2}$ peak value for the $y=0$ sample. The improvement arises because the resistivity is significantly smaller than that of the undoped sample, which is due to a combination of mineralisation and doping effects, and although $|S|$ is diminished with respect to the undoped $(y=0)$ sample, it is the largest of the three doped samples.

The thermal conductivities ( $\kappa$ ) (Fig. 4d) are largely temperature independent over the measurement range and increase by $50 \%$ with $\mathrm{Cu}$ content due to the increasing contribution from the electronic component $\left(\kappa_{\mathrm{el}}\right)$ (Fig. S5c $\dagger$ ). The lattice thermal conductivities $\left(\kappa_{\text {lat }}\right)$ (Fig. 4e) were extracted using the WiedemannFranz law using an empirical expression to estimate the Lorenz number from $S(T):{ }^{59}$ they reduce in accordance with phonon scattering by interstitial $\mathrm{Cu}$. The undoped sample has a significant bipolar contribution to $\kappa$ at temperatures above $600 \mathrm{~K}$, which is suppressed with carrier doping resulting from the $\mathrm{Cu}$ interstitials.

Primarily because of the semiconductor to degenerate semiconductor transition leading to a significant improvement in $S^{2}$ / $\rho$, the best dimensionless figure of merit (Fig. 4f) obtained was $Z T$ $=0.8$ at $773 \mathrm{~K}$ for the $y=0.025$ sample. It is also important that $\kappa_{\mathrm{el}}$ is much lower than those of the more Cu-rich samples, which more than compensates for the slightly larger $\kappa_{\text {lat }}$ values. The importance of this balance between $S^{2} / \rho$ and $\kappa_{\mathrm{el}}$ can be seen for the more degenerate samples, which show comparable $Z T$ values to the undoped sample despite their significantly larger power factors. The improvements of $S^{2} / \rho$ and $Z T$ for the $y=0.025$ sample translate directly into improved predicted device properties, ${ }^{43}$ which exceed $8 \%$ efficiency at $T_{\mathrm{h}}=773 \mathrm{~K}$ and boast a power output over $6 \mathrm{~W} \mathrm{~cm}^{-2}$, around a $50 \%$ increase for both values compared to the undoped material (shown in Fig. 5). While further addition of interstitial $\mathrm{Cu}$ doesn't translate to better efficiency, the power outputs still show significant improvements compared to the undoped sample.

\section{Modelling of the charge transport}

\section{Single parabolic band modelling}

Relevant room temperature Hall mobilities and carrier concentrations can be viewed in Table $\mathrm{S} 2 \uparrow$ and all plots
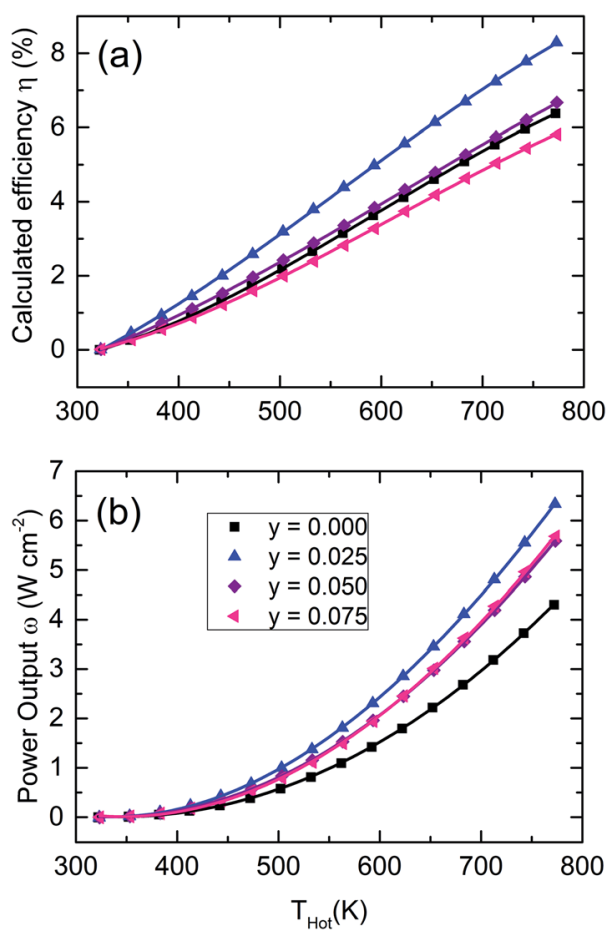

Fig. 5 (a) Calculated efficiency and (b) power output for a $2 \mathrm{~mm}$ long leg for the $\mathrm{Ti}_{0.5} \mathrm{Zr}_{0.25} \mathrm{Hf}_{0.25} \mathrm{NiCu}_{\mathrm{y}} \mathrm{Sn}$ half-Heusler alloys as a function of the hot side of the device $T_{\text {hot }}$ when the cold side is held at $T_{\text {cold }}=322$ K. 
containing Hall data are part of Fig. 6. The addition of interstitial $\mathrm{Cu}$ produces a linear increase in the Hall carrier concentration $\left(n_{\mathrm{H}}\right)$ (Fig. 6a) which can be attributed to the $\mathrm{Cu}$ $4 \mathrm{~s}^{1}$ electron directly doping the conduction band, with values of the carrier concentration being comparable to the addition of 1 electron per interstitial $\mathrm{Cu}$ (Fig. S6†). The decrease of $|S|$ as a function of $n_{\mathrm{H}}$ (Fig. 6b) shows that all samples can be characterised by a Single Parabolic Band (SPB) with an effective mass $\left(m_{\mathrm{DoS}}^{*}\right)$ of $4.1 m_{\mathrm{e}}$ (see ESI for a description of the model used $\dagger$ ). The unchanging effective mass values indicate that the addition of interstitial $\mathrm{Cu}$ does not significantly alter the conduction band structure. The DFT calculations support this rigid band picture with supercell calculations yielding a largely unchanged electronic band structure with the main effect being the n-type doping. The Hall mobility $\left(\mu_{\mathrm{H}}\right)$ almost doubles between the $y=0$ and $y=0.0125$ samples, which reflects the mineralisation effects observed for even the lowest $\mathrm{Cu}$ doping in
Fig. 3. For the doped samples $\mu_{\mathrm{H}}$ gradually decreases as a function of $n_{\mathrm{H}}$ (Fig. 6c). For further analysis, we have used the SPB model to provide theoretical fitting of the data for the doped $(y>0)$ samples. This follows published work, ${ }^{60}$ where two main intrinsic electron scattering mechanisms have been identified: by acoustic phonons and from alloy disorder, ${ }^{17}$ where the latter has also been linked to interstitial $\mathrm{Ni}^{61}$ This leads to three terms in the model used here: acoustic phonon and $\mathrm{X}$-site alloy scattering, which do not change with $y$, and scattering due to $\mathrm{Cu}$ interstitials, which is predicted to increase rapidly. Fitting reveals that the first two terms are enough to describe the experimental data for $y>0$ (Fig. 6c), while trial fits including interstitial $\mathrm{Cu}$ are shown in Fig. $6 \mathrm{~d}$ and lead to a much steeper decrease in $\mu_{\mathrm{H}}$. This demonstrates that $\mu_{\mathrm{H}}$ is not affected by $\mathrm{Cu}$ interstitials, which is consistent with the large power factors and supported by our DFT results. We note that the gradual decrease of $\mu_{\mathrm{H}}$ in Fig. $6 \mathrm{c}$ follows the expected $n_{\mathrm{H}}$
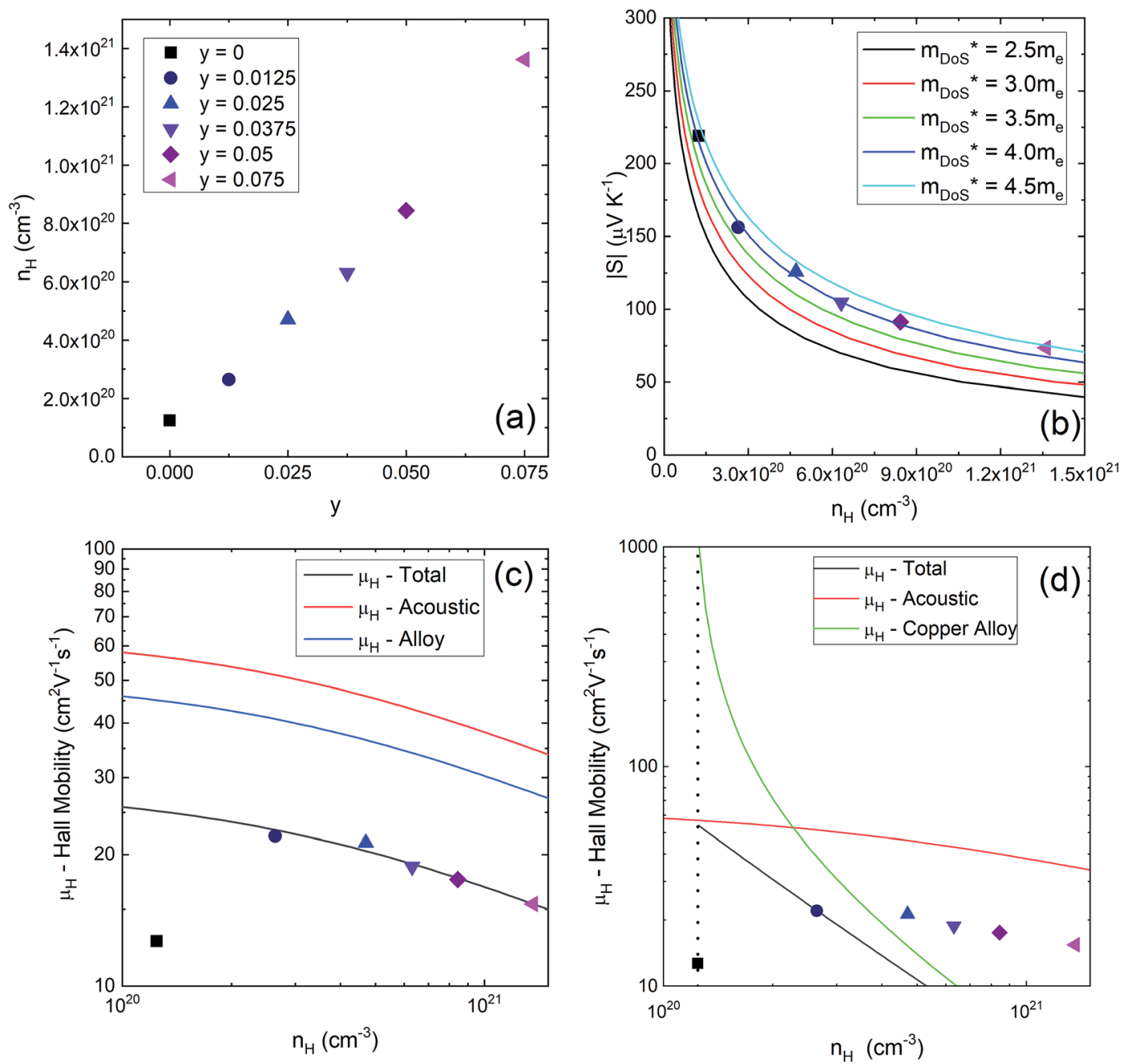

Fig. 6 Electronic transport in the $\mathrm{Ti}_{0.5} \mathrm{Zr}_{0.25} \mathrm{Hf}_{0.25} \mathrm{NiCu}_{y} \mathrm{Sn}$ half-Heusler alloys from Hall measurements. (a) The dependence of Hall carrier concentration $\left(n_{H}\right)$ on interstitial Cu content $(y)$ is nearly linear. (b) The Pisarenko plot for these samples with the trend lines predicted using the SPB model. (c) The Hall mobilities fitted using a model considering acoustic phonon and X-site alloy electron scattering, which is found to adequately describe the experimental data for the doped samples $(y>0)$. (d) Trial fits that include acoustic phonon electron scattering and an alloying-type contribution due to interstitial $\mathrm{Cu}$, which is not able to describe the experimental trend. 
dependence and does not reflect stronger coupling with phonons or alloy disorder. The strength of these interactions is characterised by the deformation and alloy scattering potentials, respectively, with fitted values $E_{\mathrm{def}}=5 \mathrm{eV}$ and $E_{\mathrm{al}}=0.2 \mathrm{eV}$, which are comparable to published data ${ }^{60}$ For our samples, the alloy scattering most likely originates from the $\mathrm{X}$-site, as there is no evidence for the presence of substantial amounts of interstitial Ni from the NPD analysis (Table S1†). Recent literature has confirmed the suppression of the electron mobility by interstitial $\mathrm{Ni}^{46,62,63}$ and our results on interstitial $\mathrm{Cu}$ are therefore highly relevant as they afford the possibility of increased phonon scattering without detriment to the electrical transport. This very different impact is supported by our DFT calculations that show the presence of in-gap states for interstitial $\mathrm{Ni}$, which provide a possible route for carrier scattering, while these are absent in the $\mathrm{Cu}$ case.

\section{DFT calculations}

The unfolded bandstructures from supercell calculations for $\mathrm{Ti}_{0.5} \mathrm{Zr}_{0.5} \mathrm{NiSn}, \mathrm{TiNi}_{1.125} \mathrm{Sn}$ and $\mathrm{TiNiCu}_{0.125} \mathrm{Sn}$ are shown in Fig. 7 and are plotted together with the dispersions for ideal TiNiSn (red line), calculated in its primitive (fcc) unit cell. This enables a direct comparison between parent and substituted compositions. The bandstructure of $\mathrm{Ti}_{0.5} \mathrm{Zr}_{0.5} \mathrm{NiSn}$ (Fig. $7 \mathrm{a}$ ) shows no significant change to the electronic structure of the parent TiNiSn, with similar bandgap and only modest changes to the conduction band dispersions. Some additional electronic states appear at the $X$ and $W$ points, but these are well separated from the Fermi energy. The relatively small changes are in-keeping with the established similarity between the bandstructures of the XNiSn parent materials. ${ }^{64,65}$ By contrast, the calculations with interstitial $\mathrm{Ni}$ and $\mathrm{Cu}$ show the emergence of a new partially filled band at the conduction band minimum ( $X$ point; Fig. $7 \mathrm{~b}$ and $\mathrm{c}$ ). The curvature of this band is sharper, suggesting a lower carrier effective mass $\left(m_{\mathrm{b}}^{*}\right)$ compared to TiNiSn. This change is not picked up in the Hall data for our samples, which have an unchanged $m_{\mathrm{Dos}}^{*}={N_{\mathrm{v}}}^{2 / 3} m_{\mathrm{b}}^{*} \sim 4.1 m_{\mathrm{e}}$ (here $N_{\mathrm{v}}=3$ is the valley degeneracy) but this may simply reflect the presence of small amounts of interstitial $\mathrm{Ni}$ in the $y=0$ sample. In addition, the Fermi energy is up-shifted by the additional electron from $\mathrm{Cu}$, which means there is a greater filling of the conduction band electron pocket. This agrees with the increase in $n_{\mathrm{H}}$ at the rate of 1 electron per interstitial $\mathrm{Cu}$ from the Hall measurements. The final and perhaps most significant observation is the absence of localised electronic defect states in the bandgap along the $X-\Gamma$ $L$ direction for interstitial $\mathrm{Cu}$ (Fig. 7c), whereas these do occur for interstitial Ni (Fig. 7b). As discussed in the previous section, the absence of these in-gap defect states, which provide a route for carrier scattering, is consistent with the unchanged electron mobility for $\mathrm{Cu}$ interstitials.

\section{Modelling of the thermal transport}

\section{Callaway modelling}

Accurate modelling of the thermal conductivity of such a complicated materials system, containing point defects in
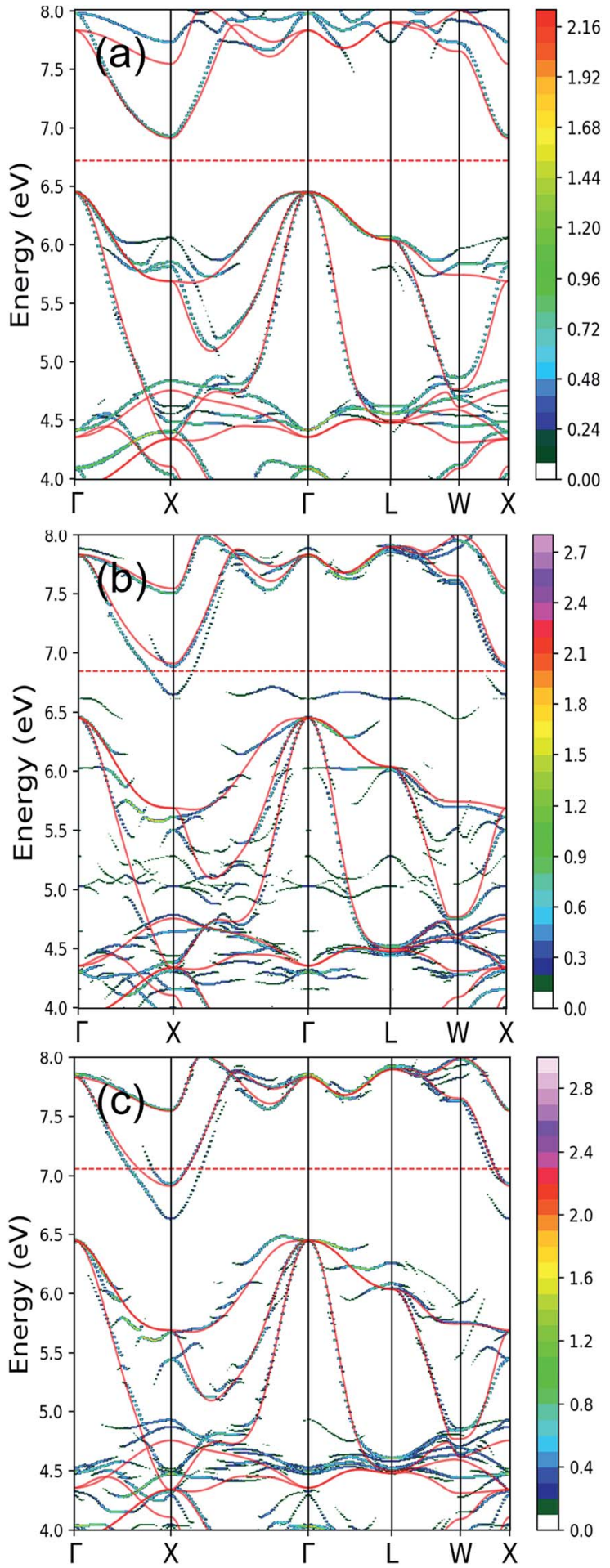

Fig. 7 Unfolded band structures of $2 \times 2 \times 2$ supercells for (a) $\mathrm{Ti}_{0.5^{-}}$ $\mathrm{Zr}_{0.5} \mathrm{NiSn}$, (b) $\mathrm{TiNi}_{1.125} \mathrm{Sn}$ and (c) $\mathrm{TiNiCu}_{0.125} \mathrm{Sn}$. The value of 1 on the colour bar corresponds to a single non-degenerate band per energy interval. The continuous red line is the band structure for TiNiSn, calculated using a primitive fcc unit cell. The dotted red line indicates the Fermi energy.

the form of alloying and interstitials, as well as microstructural inhomogeneity is both challenging and often overlooked. Theoretical work ${ }^{66}$ on defect-free $\mathrm{HH}$ alloys has 
Table 1 Calculated mass $\left(\Gamma_{\mathrm{M}}\right)$ and strain disorder $\left(\Gamma_{\mathrm{S}}\right)$ parameters for the $\mathrm{X}$-site, Callaway-model predicted and measured lattice thermal conductivities $\left(\kappa_{\text {lat }}\right)$ for the $\mathrm{Ti}_{0.5} \mathrm{Zr}_{0.25} \mathrm{Hf}_{0.25} \mathrm{NiCu}_{y} \mathrm{Sn}$ samples with no and $7.5 \%$ interstitial $\mathrm{Cu}$

\begin{tabular}{|c|c|c|c|c|}
\hline$y$ & $\Gamma_{\mathrm{M}, \mathrm{X} \text {-site }}$ & $\Gamma_{\mathrm{S}, \mathrm{X} \text {-site }}$ & Predicted $\kappa_{\text {lat }}\left(\mathrm{W} \mathrm{m}^{-1} \mathrm{~K}^{-1}\right)$ & Experimental $\kappa_{\text {lat }}\left(\mathrm{W} \mathrm{m}{ }^{-1} \mathrm{~K}^{-1}\right)$ \\
\hline 0 & 0.1575 & 0.0154 & 3.10 & $3.07( \pm 0.31)$ \\
\hline 0.075 & 0.1520 & 0.0149 & 2.50 & $2.66( \pm 0.27)$ \\
\hline
\end{tabular}
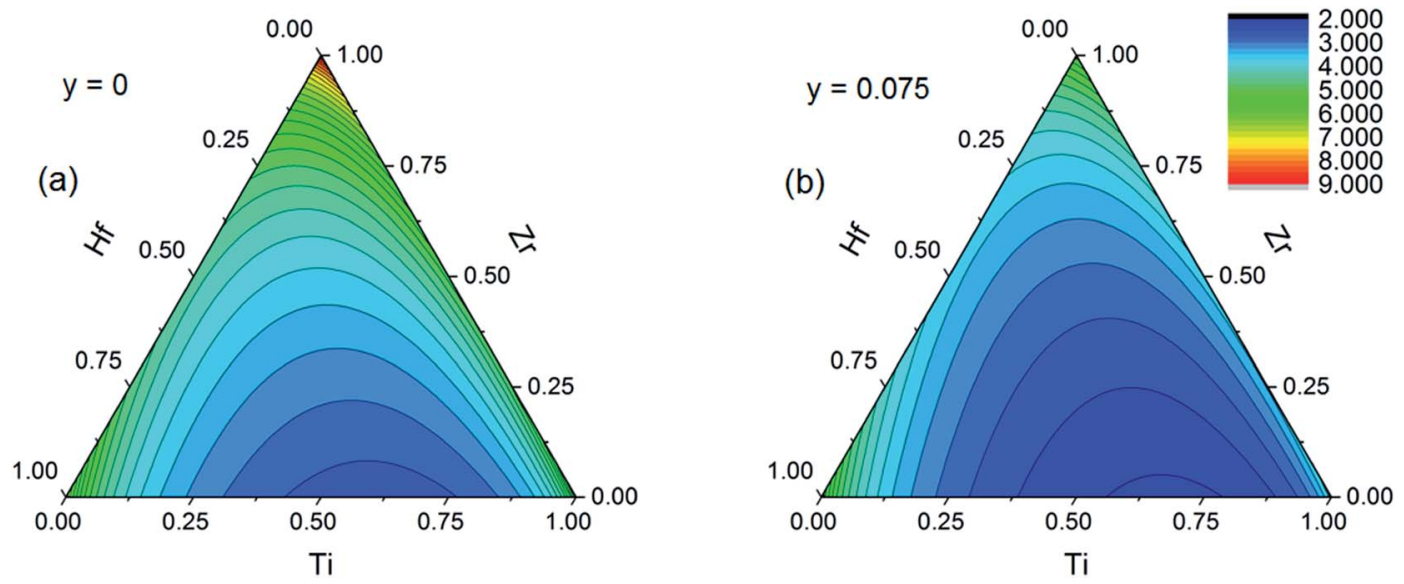

Fig. 8 Predicted lattice thermal conductivity in the ternary $\mathrm{Ti}_{a} \mathrm{Zr}_{b} \mathrm{Hf}_{C} \mathrm{NiCu}_{\mathrm{y}} \mathrm{Sn}$ half-Heusler phase diagram for two levels of interstitial Cu (y $=$ $\mathrm{O}$ and $y=0.075)$. The intensity scale is in $\mathrm{W} \mathrm{m}^{-1} \mathrm{~K}^{-1}$. The lowest $\kappa_{\text {lat }}=2.8 \mathrm{~W} \mathrm{~m}^{-1} \mathrm{~K}^{-1}(y=0)$ and $\kappa_{\text {lat }}=2.2 \mathrm{~W} \mathrm{~m}^{-1} \mathrm{~K}^{-1}(y=0.075)$ occur on the Ti-Hf axis for $\sim 30 \% \mathrm{Hf}$.

suggested that the bulk of heat carrying phonons have mean free paths less than $1 \mu \mathrm{m}$. Our microscopy has not revealed any nanostructures at significant number densities, leaving point defects as the most likely source of thermal conductivity reduction. The average grain size for $y=0$ is $\sim 2 \mu \mathrm{m}$, which is already too large to expect a significant reduction due to boundary scattering. ${ }^{18,19}$ For $y>0$, the average grain size increases, while the improved homogenisation of $\mathrm{Ti}, \mathrm{Zr}$ and Hf will maximise the point-defect disorder. We have previously described the impact of interstitials in TiNiSn and find that they embed a large disorder phonon scattering effect, comparable to the introduction of vacancies, and much stronger than conventional alloying. ${ }^{43,46}$ Here, we extend the Callaway approach and focus on the impact of alloying at fixed levels of $\mathrm{Cu}$ interstitials. This approach uses $\mathrm{XNiCu}_{y} \mathrm{Sn}$ end-members to define the thermal conductivity of a 'perfect' crystal $\left(\kappa_{\text {lat }}^{\mathrm{P}}\right)$ in the absence of point-defect phonon scattering (Table S3 $\uparrow$ ). The expected phonon scattering due to mass $\left(\Gamma_{\mathrm{M}}\right)$ and size $\left(\Gamma_{\mathrm{S}}\right)$ disorder is then calculated and used to predict a value for $\kappa_{\text {lat }}$ (ref. 67) and this can be compared to the measured values. The predicted $\kappa_{\text {lat }}$ is relatively insensitive to the imperfect mixing of the $\mathrm{X}$ elements and a statistical distribution was assumed. Table 1 summarises the results of these calculations for $y=0$ and $y=0.075$ and the conclusion is that the model predicts the measured $\kappa_{\text {lat }}$ within the uncertainty of the experimental values. This confirms that the impact of alloying is the conventional phonon point-defect scattering due to mass and size differences. The good agreement allows $\kappa_{\text {lat }}$ to be predicted for any combination of alloying elements, guiding further exploration. Pseudo ternary $\mathrm{Ti}_{a} \mathrm{Zr}_{b} \mathrm{Hf}_{c} \mathrm{NiCu}_{y} \mathrm{Sn}(y=0$ and 0.075$)$ phase diagrams illustrating the variations in $\kappa_{\text {lat }}$ due to mass and size disorder are shown in Fig. 8. The two plots have a similar form and the effect of $\mathrm{Cu}$ doping is to depress $\kappa_{\mathrm{lat}}$ for all compositions. The lowest value of $\kappa_{\text {lat }}$ is for compositions around $\mathrm{Ti}_{0.7} \mathrm{Hf}_{0.3^{-}}$ $\mathrm{NiCu}_{0.075} \mathrm{Sn}$, which provides the best balance of mass disorder, the $\kappa_{\text {lat }}$ values of the parent phases and beneficial scattering from interstitial $\mathrm{Cu}$. To best manage the electronic properties, in particular $\kappa_{\mathrm{el}}$, one would need to reduce the amount of interstitial $\mathrm{Cu}$ to $0.01<y<0.025$.

\section{Conclusions}

The incorporation of $\mathrm{Cu}$ into XNiSn $\mathrm{HH}$ alloys is a promising route to enhance their thermoelectric performance. Its presence during synthesis promotes homogenisation of $\mathrm{Ti}, \mathrm{Zr}$ and $\mathrm{Hf}$, and leads to improved grain growth, enabling a doubling of the electron mobility. This mineralising effect likely occurs via small amounts of molten $\mathrm{Cu}-\mathrm{Sn}$ alloy, which locally dissolves reagents and increases diffusion rates. In the formed products, $\mathrm{Cu}$ occupies the interstitial site at close to the nominal values. Despite the complexity of the microstructure, the trends in the thermoelectric properties of the doped samples can be largely understood by point-defect electron and phonon scattering mechanisms. $\mathrm{Cu}$ is an effective n-type dopant with a dual function as an effective phonon scatterer without detrimental impact on the electron mobility (in contrast to interstitial Ni), leading to enhanced $Z T$ values. The 
$\mathrm{X}$-site alloying causes conventional mass and size disorder phonon scattering, leading to substantial reductions in thermal conductivity, with minor reductions of the electron mobility as characterised by the low value of the alloy scattering potential in the SPB model.

\section{Maximum achievable performance}

The SPB analysis predicts that tuning the carrier concentration to $\sim 2 \times 10^{20} \mathrm{~cm}^{-3}(y \sim 0.01$; Fig. S7d $\dagger)$, will enable a $10-15 \%$ improvement, yielding $Z T \sim 0.9$ at $773 \mathrm{~K}$. Furthermore, despite our ability to model the thermoelectric trends, there could be hidden effects that are invariant across the samples. For example, comparable $\mathrm{Sb}$ doped samples prepared via meltbased routes routinely achieve $S^{2} / \rho=5-6 \mathrm{~W} \mathrm{~m}^{-1} \mathrm{~K}^{-2} \cdot{ }^{15,22}$ If similar values could be achieved in samples with interstitial $\mathrm{Cu}$ - and there is no reason why this should not be possible since interstitial $\mathrm{Cu}$ and $\mathrm{X}$-site alloying do strongly affect the electron mobility - then $Z T$ could readily be improved to above unity, and in the best-case scenario $Z T \sim 1.3$ at $773 \mathrm{~K}$ is possible. $\mathrm{Cu}$ interstitials could potentially also find application in other halfHeusler systems as n-type dopants and phonon scattering centres. Investigation of the solubility of interstitial $\mathrm{Cu}$ in other half-Heuslers, including some of the best current p-types to develop n-types based on near identical chemical compositions, is of considerable interest.

\section{Author contributions}

S. A. B. synthesised the materials, undertook thermoelectric property measurements, and analysed all diffraction data; R. J. Q. undertook the SPB and Callaway modelling, J. E. H. and D. A. M. collected and analysed all microscopy data; K. D. undertook the DFT calculations; R. I. S. and A. R. B. provided assistance with data collection at the ISIS Muon and Neutron Source and Diamond Light Source, respectively; E. D. and I. F. collected the Hall data; K. R. supervised the DFT calculations; J.-W. G. B. conceived the project, supervised sample preparation, thermoelectric characterisation, analysis of diffraction data and SPB modelling. J.-W. G. B. and D. A. M. wrote the manuscript with assistance from S. A. B, R. J. Q and K. R.

\section{Conflicts of interest}

There are no conflicts of interest to declare.

\section{Acknowledgements}

J.W. G. B. acknowledges EPSRC grant EP/N01717X/1; D. A. M. acknowledges EPSRC grants EP/N017218/1 and EP/P001483/1; and K. R. acknowledges grant EP/N01703X/1. The STFC is acknowledged for beam time at the Diamond Light Source (award EE14032) and ISIS neutron and muon facility (award RB1610148). DFT calculations were performed using STFC Scientific Computing Department's "SCARF" cluster. Raw data underpinning this work is available at DOI: 10.5525/gla.researchdata.912.

\section{References}

1 CRC Handbook of Thermoelectrics, ed. D. M. Rowe, CPC Press, Boca Raton, 1995.

2 Thermoelectrics and its Energy Harvesting, ed. D. M. Rowe, CRC Press, Boca Raton, 2012.

3 J. W. G. Bos and R. A. Downie, J. Phys.: Condens. Matter, 2014, 26, 433201.

4 J. J. Yu, K. Y. Xia, X. B. Zhao and T. J. Zhu, J. Phys. D: Appl. Phys., 2018, 51, 113001.

5 T. J. Zhu, C. G. Fu, H. H. Xie, Y. T. Liu and X. B. Zhao, Adv. Energy Mater., 2015, 5, 1500588.

6 L. H. Huang, Q. Y. Zhang, B. Yuan, X. Lai, X. Yan and Z. F. Ren, Mater. Res. Bull., 2016, 76, 107-112.

7 C. G. Fu, S. Q. Bai, Y. T. Liu, Y. S. Tang, L. D. Chen, X. B. Zhao and T. J. Zhu, Nat. Commun., 2015, 6, 8144.

8 C. G. Fu, T. J. Zhu, Y. T. Liu, H. H. Xie and X. B. Zhao, Energy Environ. Sci., 2015, 8, 216-220.

9 R. Hea, D. Kraemer, J. Mao, L. Zeng, Q. Jie, Y. C. Lan, C. H. Li, J. Shuai, H. S. Kim, Y. Liu, D. Broido, C. W. Chu, G. Chen and Z. Ren, Proc. Natl. Acad. Sci. U. S. A., 2016, 113, 13576-13581. 10 H. T. Zhu, R. He, J. Mao, Q. Zhu, C. H. Li, J. F. Sun, W. Y. Ren, Y. M. Wang, Z. H. Liu, Z. J. Tang, A. Sotnikov, Z. M. Wang, D. Broido, D. J. Singh, G. Chen, K. Nielsch and Z. F. Ren, Nat. Commun., 2018, 9, 2497.

11 J. J. Yu, C. G. Fu, Y. T. Liu, K. Y. Xia, U. Aydemir, T. C. Chasapis, G. J. Snyder, X. B. Zhao and T. J. Zhu, Adv. Energy Mater., 2018, 8, 1701313.

12 H. T. Zhu, J. Mao, Y. W. Li, J. F. Sun, Y. M. Wang, Q. Zhu, G. N. Li, Q. C. Song, J. W. Zhou, Y. H. Fu, R. He, T. Tong, Z. H. Liu, W. Y. Ren, L. You, Z. M. Wang, J. Luo, A. Sotnikov, J. M. Bao, K. Nielsch, G. Chen, D. J. Singh and Z. F. Ren, Nat. Commun., 2019, 10, 270.

13 C. Yu, T. J. Zhu, R. Z. Shi, Y. Zhang, X. B. Zhao and J. He, Acta Mater., 2009, 57, 2757-2764.

14 L. Chen, S. Gao, X. Zeng, A. M. Dehkordi, T. M. Tritt and S. J. Poon, Appl. Phys. Lett., 2015, 107, 041902.

15 M. Gurth, G. Rogl, V. V. Romaka, A. Grytsiv, E. Bauer and P. Rogl, Acta Mater., 2016, 104, 210-222.

16 S. Sakurada and N. Shutoh, Appl. Phys. Lett., 2005, 86, 082105. 17 Y. T. Liu, C. G. Fu, K. Y. Xia, J. J. Yu, X. B. Zhao, H. G. Pan, C. Felser and T. J. Zhu, Adv. Mater., 2018, 30, 1800881.

18 S. Bhattacharya, M. J. Skove, M. Russell, T. M. Tritt, Y. Xia, V. Ponnambalam, S. J. Poon and N. Thadhani, Phys. Rev. B: Condens. Matter Mater. Phys., 2008, 77, 184203.

19 G. Joshi, X. Yan, H. Z. Wang, W. S. Liu, G. Chen and Z. F. Ren, Adv. Energy Mater., 2011, 1, 643-647.

20 X. A. Yan, G. Joshi, W. S. Liu, Y. C. Lan, H. Wang, S. Lee, J. W. Simonson, S. J. Poon, T. M. Tritt, G. Chen and Z. F. Ren, Nano Lett., 2011, 11, 556-560.

21 S. Populoh, M. H. Aguirre, O. C. Brunko, K. Galazka, Y. Lu and A. Weidenkaff, Scr. Mater., 2012, 66, 1073-1076.

22 M. Schwall and B. Balke, Phys. Chem. Chem. Phys., 2013, 15, 1868-1872.

23 R. A. Downie, D. A. MacLaren and J. W. G. Bos, J. Mater. Chem. A, 2014, 2, 6107-6114. 
24 K. Kirievsky, Y. Gelbstein and D. Fuks, J. Solid State Chem., 2013, 203, 247-254.

25 A. Page, C. Uher, P. F. Poudeu and A. Van der Ven, Phys. Rev. B: Condens. Matter Mater. Phys., 2015, 92, 174102.

26 D. T. Do, S. D. Mahanti and J. J. Pulikkoti, J. Phys.: Condens. Matter, 2014, 26, 275501.

27 M. Gurth, A. Grytsiv, J. Vrestal, V. V. Romaka, G. Giester, E. Bauer and P. Rogl, RSC Adv., 2015, 5, 92270-92291.

28 J. P. A. Makongo, D. K. Misra, X. Y. Zhou, A. Pant, M. R. Shabetai, X. L. Su, C. Uher, K. L. Stokes and P. F. P. Poudeu, J. Am. Chem. Soc., 2011, 133, 18843-18852.

29 J. E. Douglas, C. S. Birkel, M. S. Miao, C. J. Torbet, G. D. Stucky, T. M. Pollock and R. Seshadri, Appl. Phys. Lett., 2012, 101, 183902.

30 Y. W. Chai and Y. Kimura, Appl. Phys. Lett., 2012, 100, 033114.

31 Y. F. Liu, P. Sahoo, J. P. A. Makongo, X. Y. Zhou, S. J. Kim, H. Chi, C. Uher, X. Q. Pan and P. F. P. Poudeu, J. Am. Chem. Soc., 2013, 135, 7486-7495.

32 C. S. Birkel, J. E. Douglas, B. R. Lettiere, G. Seward, N. Verma, Y. C. Zhang, T. M. Pollock, R. Seshadri and G. D. Stucky, Phys. Chem. Chem. Phys., 2013, 15, 6990-6997.

33 Y. W. Chai and Y. Kimura, Acta Mater., 2013, 61, 6684-6697. 34 J. E. Douglas, C. S. Birkel, N. Verma, V. M. Miller, M. S. Miao, G. D. Stucky, T. M. Pollock and R. Seshadri, J. Appl. Phys, 2014, 115, 043720.

35 J. E. Douglas, P. A. Chater, C. M. Brown, T. M. Pollock and R. Seshadri, J. Appl. Phys., 2014, 116, 163514.

36 Y. Kimura and Y. W. Chai, JOM, 2015, 67, 233-245.

37 P. Sauerschnig, A. Grytsiv, J. Vrestal, V. V. Romaka, B. Smetana, G. Giester, E. Bauer and P. Rogl, J. Alloys Compd., 2018, 742, 1058-1082.

38 M. N. Guzik, M. Schrade, R. Tofan, P. A. Carvalho, K. Berland, M. H. Sorby, C. Persson, A. E. Gunnaes and B. C. Hauback, CrystEngComm, 2019, 21, 3330-3342.

39 K. S. Kim, Y. M. Kim, H. Mun, J. Kim, J. Park, A. Y. Borisevich, K. H. Lee and S. W. Kim, Adv. Mater., 2017, 29, 1702091.

40 H. J. Lee, K. H. Lee, L. Fu, G. Han, H.-S. Kim, S.-I. Kim, Y.-M. Kim and S. W. Kim, Acta Mater., 2019, 180, 97-104.

41 R. A. Downie, R. I. Smith, D. A. MacLaren and J. W. G. Bos, Chem. Mater., 2015, 27, 2449-2459.

42 R. A. Downie, S. A. Barczak, R. I. Smith and J. W. G. Bos, J. Mater. Chem. C, 2015, 3, 10534-10542.

43 S. A. Barczak, J. E. Halpin, J. Buckman, R. Decourt, M. Pollet, R. I. Smith, D. A. MacLaren and J. W. G. Bos, ACS Appl. Mater. Interfaces, 2018, 10, 4786-4793.

44 R. A. Downie, D. A. MacLaren, R. I. Smith and J. W. G. Bos, Chem. Commun., 2013, 49, 4184-4186.
45 S. A. Barczak, PhD thesis, Heriot-Watt University, 2018.

46 S. A. Barczak, J. Buckman, R. I. Smith, A. R. Baker, E. Don, I. Forbes and J. W. G. Bos, Materials, 2018, 11, 536.

47 A. C. Larson and R. B. Von Dreele, General Structure Analysis System (GSAS), Los Alamos National Laboratory Report LAUR 86-748, 2000.

48 B. H. Toby, J. Appl. Crystallogr., 2001, 34, 210-213.

49 A. A. Coelho, J. S. O. Evans, I. R. Evans, A. Kern and S. Parsons, Powder Diffr., 2011, 26, S22-S25.

50 B. Beausir and J.-J. Fundenberger, ATOM - Analysis Tools for Orientation Maps, 2018, http://atom-software.eu.

51 C. Jeanguillaume and C. Colliex, Ultramicroscopy, 1989, 28, 252-257.

52 S. J. Clark, M. D. Segall, C. J. Pickard, P. J. Hasnip, M. J. Probert, K. Refson and M. C. Payne, Z. Kristallogr. Cryst. Mater., 2005, 220, 567-570.

53 J. P. Perdew, K. Burke and M. Ernzerhof, Phys. Rev. Lett., 1996, 77, 3865-3868.

54 P. Brommer and D. Quigley, J. Phys.: Condens. Matter, 2014, 26, 485501.

55 V. Popescu and A. Zunger, Phys. Rev. B: Condens. Matter Mater. Phys., 2012, 85, 485501.

56 S. Ishiwata, J. W. G. Bos, Q. Huang and R. J. Cava, J. Phys.: Condens. Matter, 2006, 18, 3745-3752.

57 N. Saunders and A. P. Miodownik, Bull. Alloy Phase Diagrams, 1990, 11, 278-287.

58 R. W. H. Webster, J. E. Halpin, S. R. Popuri, J. W. G. Bos and D. A. MacLaren, APL Mater., 2019, 7, 013206.

59 H. S. Kim, Z. M. Gibbs, Y. L. Tang, H. Wang and G. J. Snyder, APL Mater., 2015, 3, 041506.

60 H. H. Xie, H. Wang, Y. Z. Pei, C. G. Fu, X. H. Liu, G. J. Snyder, X. B. Zhao and T. J. Zhu, Adv. Funct. Mater., 2013, 23, 51235130.

61 H. H. Xie, H. Wang, C. G. Fu, Y. T. Liu, G. J. Snyder, X. B. Zhao and T. J. Zhu, Sci. Rep., 2014, 4, 6888.

62 W. Y. Ren, H. T. Zhu, J. Mao, L. You, S. W. Song, T. Tong, J. M. Bao, J. Luo, Z. M. Wang and Z. F. Ren, Adv. Electron. Mater., 2019, 5, 1900166.

63 Y. L. Tang, X. S. Li, L. H. J. Martin, E. C. Reyes, T. Ivas, C. Leinenbach, S. Anand, M. Peters, G. J. Snyder and C. Battaglia, Energy Environ. Sci., 2018, 11, 311-320.

64 S. Ogut and K. M. Rabe, Phys. Rev. B: Condens. Matter Mater. Phys., 1995, 51, 10443-10453.

65 M. Zahedifar and P. Kratzer, Phys. Rev. B, 2018, 97, 035204. 66 J. Shiomi, K. Esfarjani and G. Chen, Phys. Rev. B: Condens. Matter Mater. Phys., 2011, 84, 104302.

67 J. Yang, G. P. Meisner and L. Chen, Appl. Phys. Lett., 2004, 85, 1140-1142. 